\title{
Mechanical characterization of different epoxy resins enhanced with carbon nanofibers
}

\author{
P. Santos, A. Maceiras, S. Valvez, P.N.B. Reis \\ University of Beira Interior, Centre for Mechanical and Aerospace Science and Technologies (C-MAST-UBI), Depart. of \\ Electromechanical Engineering, 6201-100 Covilhã, Portugal \\ paulo.sergio.santos@ubi.pt, bttps://orcid.org/0000-0001-9026-5966 \\ alberto.maceiras@ubi.pt, bttps://orcid.org/0000-0002-1948-6560 \\ sara.valvez@ubi.pt, bttps://orcid.org/0000-0001-8285-1332 \\ preis@ubi.pt, bttps://orcid.org/0000-0001-5203-3670
}

\begin{abstract}
Epoxy with carbon nanofibers (CNFs) are effective nano enhanced materials that can be prepared by easy and low-cost method. The present paper compares the improvements, in terms of flexural and viscoelastic properties, of two epoxy resins reinforced with different weight percentages (wt.\%) of CNFs. These epoxy resins have different viscosities, and weight contents between $0 \%$ and $1 \%$ of CNFs were used to achieve the maximum mechanical properties. Subsequently, for the best configurations obtained, the sensitivity to the strain rate and the viscoelastic behaviour (stress relaxation and creep) were analysed based on international standards. It was possible to conclude that, for both resins, carbon CNFs promote significant improvements in all the studied mechanical properties, even for different contents by weight.
\end{abstract}

KEYwords. Composites; Epoxy resins; Carbon nanofibers; Mechanical properties.

\section{OPEN ACCESS}

Citation: Santos, P., Maceiras, A., Valvez, S., Reis, P.N.B., Mechanical characterization of different epoxy resins enhanced with carbon nanofibers, Frattura ed Integrità Strutturale, 55 (2021) 198-212.

Received: 27.10 .2020

Accepted: 08.12 .2020

Published: 01.01.2021

Copyright: (C) 2021 This is an open access article under the terms of the CC-BY 4.0, which permits unrestricted use, distribution, and reproduction in any medium, provided the original author and source are credited.

\section{INTRODUCTION}

$\mathrm{E}$ poxy resins are a class of thermosetting polymers frequently used as matrices in polymeric composites due to their interesting characteristics, such as dimensional stability, chemical resistance, good stiffness, high specific strength and good adhesion to various types of reinforcements [1,2]. Epoxy resin is a thermostable polymer consisted of two principal parts: resin and hardener. Diglycidyl ethers of bisphenol-F and/or bisphenol-A are the main elements of the most normal epoxy resins. Hardeners are curing agents that react with a resin and become part of the solid final epoxy through cross-linking chemical reaction when these two chemicals are mixed together [3]. These curing compounds can have different types of molecules such as amines, amideamines, anhydrides, carboxylic acids, polyamides or imidazoles. These molecules have in common that they are able to initiate the polymerization process when their reactive hydrogen or hydroxyl group that react with the oxirane (epoxy) rings. 
Amines are one of the most frequent and important curing agents. The range of alternatives is huge since they are present in different chemical configurations. Amines can have two free hydrogens (primary amine), one free hydrogen (secondary) or no hydrogens (tertiary), and they may have a cyclic benzene structure (aromatic) or straight chains (aliphatic). In general, for low-temperature curing systems like adhesive or coatings, aliphatic primary and secondary are the most used, whereas, for fibre-reinforced composites, aromatic amines are chosen. Primary amines react speedily at room temperature with epoxies, through epoxy ring-opening, and the thermosetting results in highly cross-linked networks with short curing life and high curing rates. Aromatic curing agents react more slowly but impart higher general stability than their aliphatic amine counterparts. In his case, the resulting system needs longer curing time and higher temperature to reach optimum properties, but their chemical resistance, electrical, mechanical and heat resistance is better. Therefore, different types of amines that can be used present advantages and disadvantages, commercial hardeners contain a mixture of different types to broader its applicability [4]. Apart from the resin and the hardener, commercial epoxies present diluents as other important components. Diluents are low-viscosity and low-molecular-weight molecules applied to reduce the viscosity and enhance the resinhardener solubility. Normally, these compounds do not leach or outgas during thermal-vacuum exposure because amid curing reactions are being combined and linked chemically with the resin [5].

Despite having many desirable properties, neat epoxies typically have low mechanical toughness. In the last few decades, a wide range of nano filers has been added to commercial epoxy resin to increase the mechanical properties, such as clays [6], alumina [7], graphene nanoplatelets (GNPs) [8], carbon nanotubes (CNTs) and carbon nanofibers (CNFs) [9, 10]. Enhancement in mechanical properties of CNFs based epoxy composites have been well illustrated in the literature by the achievement of good dispersion of additives within the matrix and maximized interfacial adhesion is required to ensure uniform stress distribution, [11-13]. CNFs are carbon-based materials that present good compatibility with many polymer matrixes, and they can be disseminated following anisotropic and isotropic distributions. Their chemical structure, good qualities, and versatility are responsible for the outstanding thermal and electrical conductivity, a mechanical performance that can be introduced in a huge variety of matrices of different origins such as metals, ceramics and polymers.

If literature presents benefits when the resin is filled by $\mathrm{CNFs}$, it also evidences that the same are sensitive to the strain rate. There exist some previous works in nano-enhanced resins with CNFs about the strain rate effect on mechanical properties. Zhou et al. [14], for example, observed that in uniaxial tensile tests, neat and CNFs modified epoxy are strain rate dependent materials and the elastic modulus and tensile strength of the materials both increased with higher strain rates between 0.00033 and $0.033 \mathrm{~s}^{-1}$. Proveda et al. [15] observed for a CNFs/epoxy resin, under compression for $5 \times 10^{-3}-2800 \mathrm{~s}^{-1} \mathrm{strain}$ rates, that the strength and modulus increased by a maximum of 180.7 and $241.7 \%$, respectively. Nevertheless, for longterm applications, composites based on polymers have the limitation of suffering stress relaxation and creep. According to the open literature, for example, in polymers there are mainly two mechanisms involved in stress relaxation: a) molecular rearrangements that demand little primary breakage or bond arrangement (physical stress); and b) crosslink formation, scission, or chain scission (chemical stress). On the other hand, creep is the combined result of the viscous flow and elastic deformation and happens because of the molecular rearrangements in the backbone and depends on the stress degree.

Therefore, the main goal of this work is to compare sensitive to the strain rate, stress relaxation and creep behaviour of two commercial epoxy resins and understand the influence of CNFs as nano-reinforcements. For this purpose, several percentages by weight of CNFs were mixed in two different resins by the technique of mechanical agitation and simultaneously the application of ultrasound. Both resins are widely used in the automotive and aeronautical sector. The bending mode was selected for this study because is the type of analysis with greater sensitivity and one of the most employed in the field.

\section{MATERIALS AND EXPERIMENTAL PROCEDURE}

wo types of epoxy resin were used to produce nanocomposites enhanced by CNFs. For this purpose, an epoxy resin
SR 8100 and a hardener SD 8822, both supplied by Sicomin, and an epoxy resin AH 150 and a hardener IP 430 ,
both supplied by Ebalta, were selected due to their different viscosities, as reported in Tab. 1. Epoxy-based materials are very interesting from an engineering point of view because of their properties and characteristics are directly controlled by their molecular structures. Epoxy resins thanks to their two main components implementation are available in a range of molecular structures, suitable for reaction with a large variety of different curing agents, for a multitude of end uses. Therefore, in order to control and understand the mechanical behaviour of these materials is a key factor to know their composition (chemical structures), and relative quantities of their components. In this work, both epoxy materials were purchased from a private company and part of the data is protected by intellectual property. Unfortunately, not all the components and quantities are disclosed in their technical datasheet to the general public. For the Sicomin SR 8100/SD 8824 the information was more detailed than for the Ebalta AH 150/IP 430, as the resin relative composition and 
the hardener chemical components were not indicated for the latter one. In this sense, Tab. 2 summarizes all the known relevant information about the chemical compositions of the two resin formulas obtained from the datasheet, and Fig. 1 shows their chemical structures.

\begin{tabular}{cccc}
\hline Property & & Sicomin SR 8100/SD 8824 & Ebalta AH 150/IP430 \\
Colour & & Light yellow liquid & Opaque \\
Viscosity $\left(@ 25{ }^{\circ} \mathrm{C}\right)$ & {$[\mathrm{mPa} \times \mathrm{s}]$} & $285 \pm 60$ & $250 \pm 50$ \\
Density at $20{ }^{\circ} \mathrm{C}$ & {$\left[\mathrm{g} / \mathrm{cm}^{3}\right]$} & - & $1.13 \pm 0.02$ \\
Modulus of elasticity & {$\left[\mathrm{N} / \mathrm{mm}^{2}\right]$} & 2970 & $3400 \pm 300$ \\
Maximum resistance & {$\left[\mathrm{N} / \mathrm{mm}^{2}\right]$} & 108 & $125 \pm 1.2$ \\
Elongation at max. load & {$[\%]$} & 4.9 & - \\
Elongation at break & {$[\%]$} & 11.8 & $5.9 \pm 0.1$ \\
Charpy impact strength & {$\left[\mathrm{kJ} / \mathrm{m}^{2}\right]$} & 52 & $60 \pm 6$ \\
Glass transition $/ \mathrm{DCC}$ & {$\left[{ }^{\circ} \mathrm{C}\right]$} & 63 & - \\
Water absorption $48 \mathrm{~h} / 70{ }^{\circ} \mathrm{C}$ & {$[\%]$} & 1.2 & - \\
\hline
\end{tabular}

Table 1: Main mechanical and physical properties of the epoxy resins.

\begin{tabular}{|c|c|c|c|}
\hline $\begin{array}{l}\text { Type of } \\
\text { component }\end{array}$ & $\begin{array}{l}\text { Identification } \\
\text { number }\end{array}$ & Sicomin SR 8100/SD 8824 & Ebalta AH 150/IP430 \\
\hline \multirow{4}{*}{ Resin } & \multirow{2}{*}{$\begin{array}{l}\text { CAS: } 1675-54-3 \\
\text { EC: } 216-823-5\end{array}$} & \multicolumn{2}{|c|}{ bisphenol A epoxy resin (DGEBA) } \\
\hline & & Composition: $10<=\mathrm{x} \%<25$ & $\begin{array}{c}\text { Composition: } \% \text { not specified } \\
\text { MW } \leqslant 700\end{array}$ \\
\hline & CAS.: 9003-36-5 & \multicolumn{2}{|c|}{ bisphenol F epoxy resin (DGEBF) } \\
\hline & EC: 500-006-8 & Composition: $50<=\mathrm{x} \%<100$ & $\begin{array}{c}\text { Composition: } \% \text { not specified } \\
\text { MW } \leqslant 700\end{array}$ \\
\hline \multirow{2}{*}{ Diluent } & CAS: $16096-31-4$ & \multicolumn{2}{|c|}{ 1,6-bis(2,3-epoxypropoxy)hexane } \\
\hline & EC: $240-260-4$ & Composition: $10<=\mathrm{x} \%<25$ & Composition: $\%$ not specified \\
\hline \multirow{5}{*}{$\begin{array}{l}\text { Hardener: } \\
\text { amines }\end{array}$} & CAS: $15520-10-2$ & 2-methylpentane-1,5-diamine & \multirow{5}{*}{$\begin{array}{c}\text { Composition: Molecules and } \% \\
\text { not specified }\end{array}$} \\
\hline & EC: $239-556-6$ & Composition: $25<=\mathrm{x} \%<50$ & \\
\hline & CAS: $1477-55-0$ & m-phenylenebis(methylamine) & \\
\hline & EC: $216-032-5$ & Composition: $25<=\mathrm{x} \%<50$ & \\
\hline & $\begin{array}{l}\text { CAS: } 39423-51-3 \\
\text { EC: } 500-105-6\end{array}$ & $\begin{array}{l}\text { trimethylolpropane tris[poly(propylene glycol), amine } \\
\text { terminated] ether } \\
\text { Composition: } 2.5<=\mathrm{x} \%<10\end{array}$ & \\
\hline
\end{tabular}

Table 2: Chemical composition of the epoxy resins, diluent and hardeners used in this study based on the data known from their technical datasheets.

Regarding the carbon nanofibers (CNFs), their technical specifications are summarized in Tab. 3 and Fig. 2 shows the SEM images of the CNFs used in this study. In terms of dimensions, as shown, the average diameter is about $130 \mathrm{~nm}$, the length ranges from 20 to $200 \mu \mathrm{m}$ and the average specific surface area around $54 \mathrm{~m}^{2} / \mathrm{g}$.

In terms of manufacture process, and after weighing, CNFs were added to the epoxy resin and several contents by weight were studied: $0.25,0.5,0.75$ and $1 \%$. The dispersion into the resin was conducted using, simultaneously, a high-speed shear mixer at a shear rate of $1000 \mathrm{rpm}$ and sonication (using an ultrasonic bath with a frequency of $40 \mathrm{kHz}$ ) for $3 \mathrm{hours}$ at room temperature. This procedure took another 10 minutes, with a rotation speed of just $150 \mathrm{rpm}$, to mix the hardener into the system. The low rotation speed aimed to minimize the formation of air bubbles and to promote only a homogeneous mixture of the hardener into the system. The rotation speed and time of mixture were optimized in previous studies. The 
mixture was again degassed in a vacuum oven to remove remaining air bubbles and then poured into a cardboard mould with dimensions of $100 \times 130 \times 3 \mathrm{~mm}^{3}$. Finally, all nanocomposites produced with Sicomin resin were cured at room temperature for 24 hours and subjected to a post-cure at $40^{\circ} \mathrm{C}$ for 24 hours, while those that were produced with Ebalta resin were cured at room temperature for 48 hours and subjected to a post-cure at $80^{\circ} \mathrm{C}$ for 5 hours.

a) Epoxy Resins<smiles>CCOc1ccc(C(C)(C)c2ccc(OCC(O)COc3ccc(C(C)(C)c4ccc(C)cc4)cc3)cc2)cc1</smiles>

b)<smiles>COc1ccc(Cc2ccc(OCC(O)COc3ccc(Cc4ccc(OCC5CO5)cc4)cc3)cc2)cc1</smiles>

c)<smiles>C(CCCOCC1CO1)CCOCC1CO1</smiles>

Hardeners: amines

d)<smiles>CC(CN)CCCN</smiles>

e)<smiles>NCc1cccc(CN)c1</smiles>

f)<smiles>C=C(N)COCC(CC)(COCC(C)N)COCC(C)N</smiles>

Figure 1: Chemical structures of (a) Bisphenol A epoxy resin (DGEBA), (b) Bisphenol F epoxy resin (DGEBF), (c) 1,6-bis(2,3epoxypropoxy)hexane, (d) 2-methylpentane-1,5-diamine, (e) m-phenylenebis(methylamine) and (f) trimethylolpropane tris[poly(propylene glycol), amine terminated] ether.

\begin{tabular}{cc}
\hline Property & Value \\
Assay & $>98 \%$ carbon basis \\
Form & Platelets $($ conical $)$ powder \\
Diameter $\times$ length & $100 \mathrm{~nm} \times 20-200 \mu \mathrm{m}$ \\
Average diameter & $130 \mathrm{~nm}$ \\
Impurities & $<14,000 \mathrm{ppm}$ iron content \\
Pore size & $0.12 \mathrm{~cm}^{3} / \mathrm{g}$ average pore volume \\
Surface area & $89.3 \AA$ average pore diameter \\
mp & Average specific surface area $54 \mathrm{~m}^{2} / \mathrm{g}$ \\
Density & $3652-3697{ }^{\circ} \mathrm{C}$ \\
Bulk density & $1.9 \mathrm{~g} / \mathrm{mL}$ at $25^{\circ} \mathrm{C}$ \\
\end{tabular}

Table 3: Technical specifications of the CNFs used in this study.

For the tests to be performed, the samples were obtained from the original plates to specimens with the dimensions and geometry shown in Fig. 3. Following the recommendations of the European Standard EN ISO 178:2003, three-point 
bending (3PB) static tests were carried out at room temperature and using a span length of $50 \mathrm{~mm}$. An Autograph AGS-X universal testing machine, from Shimadzu, with a $10 \mathrm{kN}$ load cell and a displacement rate of $2 \mathrm{~mm} / \mathrm{min}$ was used to test six different samples for each configuration.

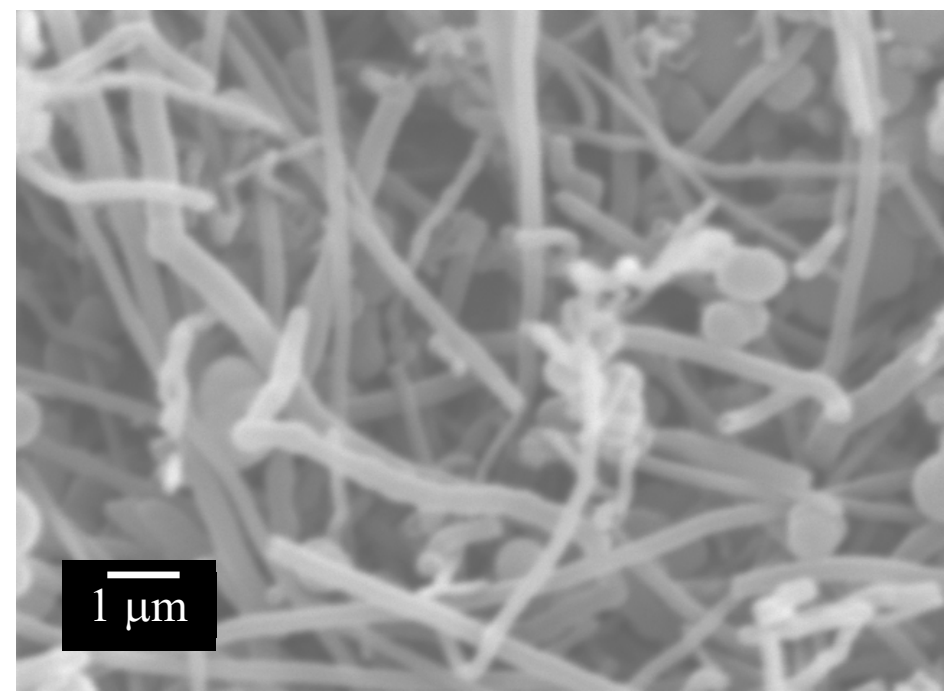

Figure 2: SEM images of the CNFs used in this study.
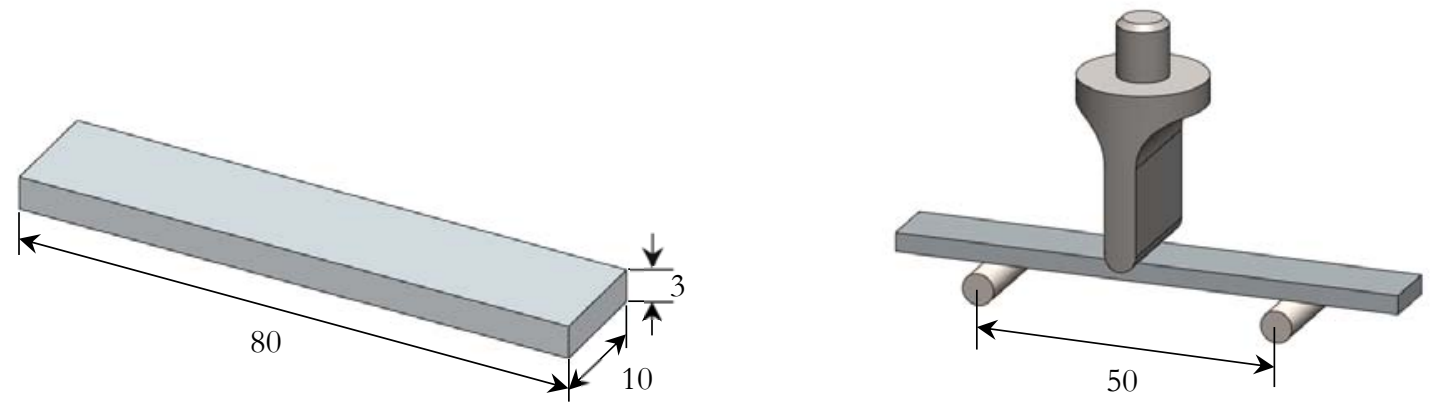

a)

b)

Figure 3: a) Geometry of the specimens; b) Three-point bending apparatus. All dimensions in mm.

The bending strength was obtained from the nominal stress at the central span section by:

$$
\sigma=\frac{3 P L}{2 b b^{2}}
$$

where $P$ is the load, $L$ the span length, $b$ the width and $b$ the thickness of the sample. The stiffness modulus was determined from the linear elastic bending beams theory relationship:

$$
E=\frac{\Delta P L^{3}}{48 \Delta u l}
$$

where $I, \Delta P$ and $\Delta u$ are, respectively, the moment of inertia of the cross-section, the load range and flexural displacement range in the middle span for an interval in the linear region of the load versus displacement plot. Finally, the flexural strain was calculated according to the European Standard EN ISO 178:2003 by the following equation:

$$
\varepsilon_{f}=\frac{6 S h}{L^{2}}
$$


where $S$ is the deflexion, $L$ the span length and $h$ the thickness of the specimen. Displacement rates of 200, 20, 2, 0.2 and $0.02 \mathrm{~mm} / \mathrm{min}$ were employed, which corresponds to strain rates $(\dot{\varepsilon})$ of $9.7 \times 10^{0}, 9.7 \times 10^{-1}, 9.7 \times 10^{-2}, 9.7 \times 10^{-3}, 1.3 \times$ $10^{-4} \mathrm{~s}^{-1}$ according to Eqn. (4):

$$
\dot{\varepsilon}=\frac{d \varepsilon_{f}}{d t}=\frac{6 V_{T} h}{L^{2}}
$$

In this equation $\dot{\varepsilon}$ is the peripheral fibre strain, $t$ is the time, $V_{T}$ is the cross-head speed, $L$ the span length and $\mathrm{h}$ the thickness of the specimen. For each condition, six specimens were tested.

Finally, the same machine was used to carried out stress relaxation and creep tests, at room temperature and with similar samples to those shown in Fig. 3. For the first tests a fixed displacement was applied, and the stress recorded during the loading time, while for creep tests a fixed stress was applied and the displacement registered during the loading period. For both resins, a bending stress of $50 \mathrm{MPa}$ was considered in order to ensure that all tests were carried out on the elastic region of the bending stress-strain curve.

\section{RESULTS AND DISCUSSION}

$\mathrm{S}$ tatic bending tests were performed according to the experimental procedure described in the previous section and with a strain rate $(\dot{\varepsilon})$ of $9.7 \times 10^{-2} \mathrm{~s}^{-1}$ (corresponding to a displacement rate of $2 \mathrm{~mm} / \mathrm{min}$ ), in order to find the best amount of nano reinforcement to maximize the bending properties. In this context, Fig. 4 presents typical flexural stress-strain curves obtained for different conditions, but they are representative of all curves obtained in this analysis.

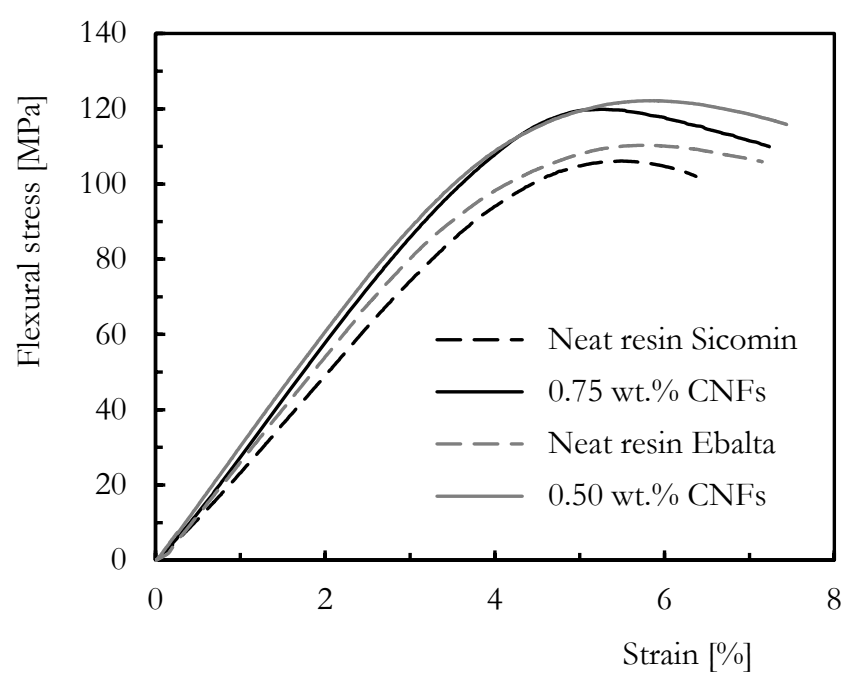

Figure 4: Representative flexural stress-strain curves obtained for $9.7 \times 10^{-2} \mathrm{~s}^{-1}$. Comparison between neat and the best nano enhanced resin.

In all curves, a linear increase in the bending stress with the strain (linear elastic region) is observed, followed by a nonlinear performance where the maximum bending stress is reached. After the peak load, the bending stress drop significantly, evidencing the imminent collapse of the nanocomposites. Fig. 5 summarizes the main bending properties, obtained from these curves, in terms of average values (symbols) and respective maximum and minimum values (dispersion bands). For both resins, it is noticed that the increase in CNFs promotes higher values of bending strength, but after a certain content of nanoparticles these values decrease due to the aggregates/agglomerates that have occurred due to intermolecular interactions (van der Waals forces and chemical bonds). While the maximum bending stress occurs with $0.75 \mathrm{wt} . \%$ of CNFs for the Sicomin resin, this property reached its maximum for $0.5 \%$ of CNFs when the Ebalta resin is considered. In comparison with the control samples (neat resin), an increase around $11.7 \%$ was observed for both resins.

In fact, according to the open literature, agglomerations/aggregations are expected for higher filler contents, which, in addition to being treated as defects, are responsible for significant concentrations of stresses in nanocomposites [16-18]. They also reduce the interfacial area between the polymeric matrix and nanoparticles, which reduces the mechanical 
involvement of polymeric chains in the nanoparticles [19]. On the other hand, only a few polymer molecules can penetrate between the nanoparticles, which promotes an exceptional increase in viscosity, even for relatively low filler contents [20]. However, due to the higher viscosity of the Sicomin resin (compared to Ebalta), it was expected to obtain the highest flexural strength with lower content of CNFs. Regardless of Fiedler et al. [21] report that the low viscosity of a resin allows a better organization of the nanoparticles, they also consider that the manufacturing process as well as the properties of the particles and matrix are determinants in the interfacial strength of the composite and dispersibility of the fillers during the production.
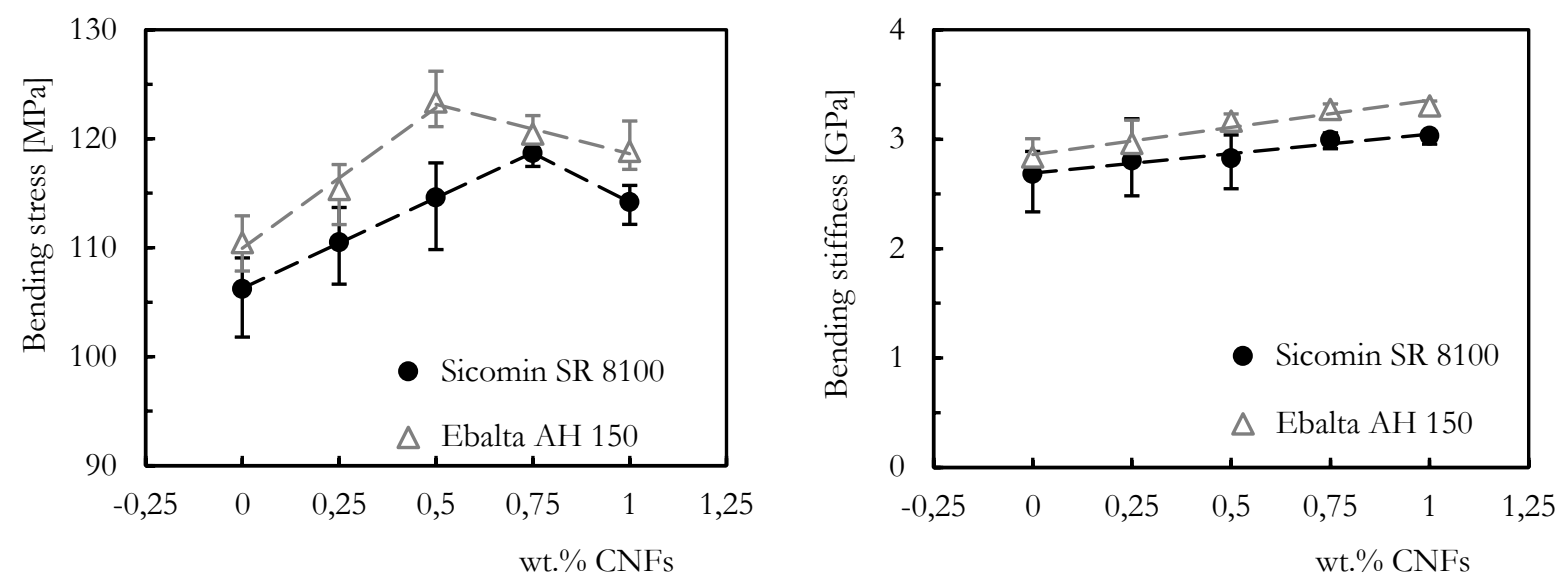

a)

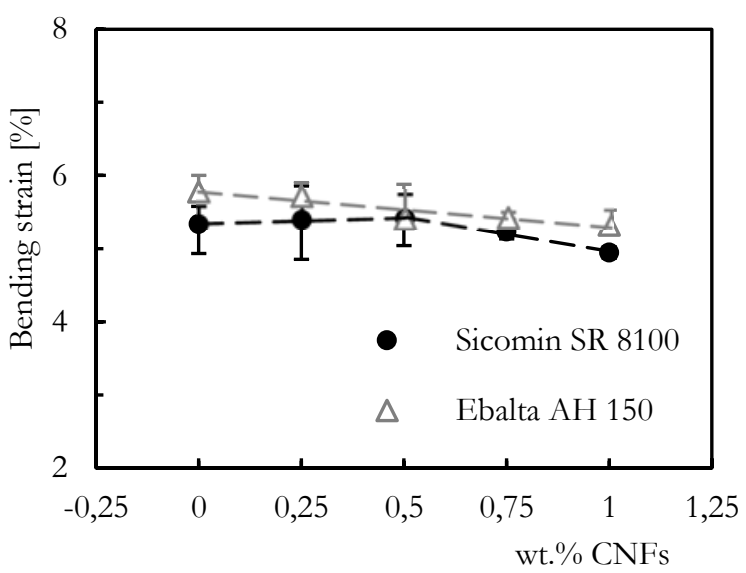

b)

c)

Figure 5: Nano enhanced resin Sicomin SR 8100 and Ebalta AH 150 with different percentages of CNFs: (a) Bending stress; (b) Bending stiffness; (c) Bending strain.

Although CNFs are considered ideal materials for reinforcing polymers due to their excellent mechanical properties, a good interaction between reinforcement CNFs and polymer matrix is necessary to obtain composites with optimal properties. For that reason, the knowledge of the chemical composition of resins and hardeners is essential to understand the physicochemical interactions between the matrix and the fillers, in order to overcome possible incompatibilities and to optimize the composite mechanical behaviour [22]. However, from the chemical point of view, both resins are based on the same components, bisphenol A (DGEBA) and bisphenol F epoxy resin (DGBF), respectively. The most relevant and employed epoxy resin is the DGEBA, which results from the chemical reaction of bisphenol A with epichlorohydrin. Manufactured DGEBA resin usually presents a distribution of molecular weight and a certain preference to have a crystalline solid material when is stored at room temperature. But, DGEBF is usually less viscous and once cured has greater toughness and flexibility. Nonetheless, although the use of both resins is indicated in their technical datasheets, there exists a lack of information about the exact proportion of both components and their molecular weight in the final commercial products (Sicomin SR 8100 and Ebalta AH 150). These differences in the epoxy resin compositions (DGEBF/DEBA), molecular 
weights and the quantity of diluent [1,6-bis(2,3-epoxypropoxy)hexane] probably explain the different viscosity referenced for Sicomin Sr $8100(285 \pm 60 \mathrm{mPa} \times \mathrm{s})$ and Ebalta AH $150(250 \pm 50 \mathrm{mPa} \times \mathrm{s})$ resins at $25^{\circ} \mathrm{C}$ in their datasheets.

With respect to hardeners, the situation is more difficult because there was no information about the composition in the Ebalta technical datasheet. As it was explained before, hardeners based on amines as curing agents become part of the chemical structure of the solid epoxy through cross-linking after reacting with a resin. Therefore, the influence in the general properties of the materials is at least as much important as the resins. For instance, to obtain the best properties it is necessary an optimum curing reaction, which implies that the amount of curing reagent employed must be stoichiometric. The number of epoxy groups and reactive hydrogens of the hardener must be equal, which is the amine molecular weight divided by the number of hydrogens (amine-equivalent weight, AEW) [23].

The curing process and the chemical phenomena of cross-linking are responsible for many of the properties of the solidstate in epoxy derived materials. The cross-link density is the spacing between successive cross-link sites, and normally, when the cross-link density increases, the glass transition temperature, thermal stability, and chemical resistance increase, but the fracture toughness and the strain to failure decreases [24]. Therefore, during the curing reaction was observed a difference of colour with a naked eye between the two resin materials, light yellow liquid (Sicomin SR 8100/SD 8824) and opaque (Ebalta AH 150/IP 430). This difference of colour can be explained because of the different hardeners formulations since both resin products are based on the same two polymers (DGEBA and DGBF). The introduction of new molecular chains of different lengths, with pendant groups, aliphatic or aromatic elements, vary many physicochemical and solid-state properties of the composites. For example, heterocyclic and aromatic curing reagents are responsible for higher temperature stabilities than their aliphatic amine alternatives [25]. An increment in the flexible amine content decreases the tensile and flexible strength related to a reduced crosslinking density [26]. In summary, the higher modulus of elasticity and maximum resistance of the Ebalta AH 150/IP 430 over the Sicomin SR 8100/SD 8824, referenced in these neat cured resins, could be explained from the different chemical relative composition (DGEBA/DGBF) of both resins, and for their different hardeners employed.

In the case of epoxy resins reinforced with $\mathrm{CNFs}$ the introduction of $\mathrm{CNF}$ s was aimed to enhance the mechanical properties of the two epoxy materials. Properties of composites are ruled not only by the carbon fibre, the resin matrix, but also are influenced by the interface formed between the two constituents. Favourable interfacial adhesion can efficiently transfer stress from matrix to fillers, which plays a key role in the mechanical properties as well as the reliability [27]. Although carbon nanofibers are increasingly used in various industries, these materials present some drawbacks. The smooth pristine surface of carbon fibre is non-polar and affects the interfacial adhesion between carbon fibres and resin matrix, which has a negative effect on the overall performance. The composite interfacial shear strength reflects the load transfer efficiency between the nanofibers and the resin, and has a relevant function in the mechanical properties. The general idea is to reach an efficient load transfer between both constituents to strengthen the nanofiber-matrix interface to overcome the lack of good interfacial bonding limited by the non-polar and smooth surface of CNFs. The fillers-resin adhesion may require strengthened by treating the fillers with a coupling agent or functionalization that bridges their molecules together. Then, the creation of covalent bonds or van der Waals forces of attraction would enhance the adhesion between the two materials (fillers/matrix) [28, 29].

Advances in interfacial improvement have been made, but the mechanisms of interfacial adhesion are difficult to be fully understood. The most common explanations for enhancement mechanisms by fillers are: a) stiffer matrix/fibres interfaces with a higher shear modulus are formed, which promotes the stress transfer; b) the presence of fibres in the interface assists in holding back excessive stress spreading in the flaw and provides a crack deflection mechanism; c) chemical interaction among CNFs, sizing and resin matrix can be improved when the nanoparticles are modified with a surface modifier. In this context, a uniform dispersion and good wetting of the nanofibers within the matrix are necessary to ensure maximum utilization of the nanofibers' characteristics, because a good CNFs dispersion can be critical to obtaining a homogeneous dispersion. High shear mixing, ultrasonication, the employment of surfactants, or the dilution method are some of the alternatives [30,31]. According to the results, $0.75 \mathrm{wt} . \%$ of $\mathrm{CNFs}$ is the content that promotes the maximum bending stress for the Sicomin resin, while for Ebalta resin is $0.5 \%$ of CNFs. Since the mixture and dispersion procedure was exactly the same, in both commercial pre-cured resins, the difference in the filler percentage values can be attributed to variation in the matrix-fibre interfaces that modify the stress transfer and spreading in the flaws and crack deflection. Normally, the variation in the interfaces can be explained by different factors, such as a) diverse aggregation formation, b) different chemical composition of the polymer matrixes and hardeners, and c) the effect of fillers on the kinetics of epoxy cure.

As was explained previously, in this work both commercial matrixes have very similar compositions, the same two epoxy materials and diluent. The exact composition is not known because are protected by copyrights, but to the best of our knowledge are analogous due to the information disclosed in datasheets. Probably, the variation in their relative compositions is responsible for the different viscosity previous curing. In theory, in less viscous fluids (Ebalta) a uniform 
dispersion of the nanofibers within the matrix would be easier to perform, limiting the tendency to form CNFs agglomerates, which are responsible for an excessive stress concentration and origin of flaws. Nonetheless, from our results, the difference in viscosities does not seem a relevant parameter, because the maximum percentage in Ebalta $(0.5 \%)$ is lower than in Sicomin $(0.75 \%)$. Therefore, the difference in filler acceptance from the matrix should be attributed to greater physicochemical compatibility of the Sicomin and not the viscosity. What is different is the hardener chemical formula composed of different types of amine molecules. The difference in composition affects clearly many parameters in pristine epoxies and it is more relevant when the parameter of fillers appears.

Surface polarity is one of the most important physicochemical attributes of both materials that affect the interface quality of the filler/matrix. However, due to their important polarity and attractive forces formed between the resin and the other material, epoxies adhere satisfactorily to multiple surfaces. Normally, strong polar attractions or direct bonds that can be formed between reactive sites in the resin and polar sites on the surface of the filler. Most inorganic materials (metals, minerals, glasses, ceramics) have some polarity so they have high surface energy, whereas organic polymer surfaces are generally less polar (more covalent) and lower surface energy [32,33].

In a very wide range of epoxy resins, polarity varies depending the molecules and curing conditions involved. The nonepoxy part of the chemical structures presents multiple possibilities, because it may have aromatic, cycloaliphatic and/or aliphatic molecules that vary its polarity and general properties. In the same way for the amines, i.e. cross-linking and chain extension reagents. The amino group shows some polar character because the $\mathrm{N}-\mathrm{H}$ bonds are more electronegative than the $\mathrm{C}-\mathrm{H}$ bonds [34]. On the other hand, pristine $\mathrm{CNFs}$ are basically non-polar materials, i.e. a molecule where the electrons between the two atoms are equally shared or where the polar bonds of the global structure are symmetrically disposed. Therefore, despite the great properties of these nanofibers, CNFs/epoxy composites can have unsatisfactory mechanical properties because CNFs have poor interfacial adhesion due to their non-polar surface. In short, the different hardeners (several amine molecules) could affect the overall polarity of the epoxy cured materials which as a relevant effect in the fillers/resin compatibility. In the optimum based nanocomposites $(0.5 \%)$, the matrix/fibres interface interaction is worse than in Sicomin (0.75\%), which has an impact on the CNFs percentage that can accept before having a detrimental effect on the mechanical characteristics, such as bending stress.

Other possible explanation, apart from polarity mismatch, is the effects of CNFs fillers on the curing processes, since it is accepted that the physicochemical and thermo-mechanical characteristics of the cured epoxy resin depend on the curing reaction conditions (temperature and time), degree of cure (curing extent) and network of crosslinking. Since the overall characteristics arises in great part from the curing reactions, their curing kinetics should be studied by Differential Scanning Calorimetry (DSC). For example, Tao et al. [35] reported that carbon nanotubes (CNTs) are able of modifying the curing process, initiating the curing reactions at inferior temperatures with respect to a neat epoxy resin. The presence of CNTs modified the curing kinetics, reduced the crosslinking density and the glass transition temperature [36]. Silanized CNFs exhibited lower peak temperature as well as higher heat of cure, and maximization in the cure reaction rates at the very initial stage of the reaction compared to those without the pristine CNFs. The curing and post-cure procedures for Sicomin and Ebalta resins in terms of temperature and time were obtained from their datasheets and were optimized from the manufacturers for neat epoxy formulas, i.e. without fillers, in this case, CNFs. That means the curing mechanism should be corroborated and maybe optimized for each filler content [37].

In this context, because the resin was the only different variable in this study, it is possible to conclude that Ebalta enables the formation of stronger covalent bonds and/or polar interactions between the resin and the CNFs. On the other hand, higher specific surface area already encourages the formation of agglomerates due to the intermolecular interactions. In terms of bending stiffness, and for Sicomin neat resin, the maximum valor is about $2.68 \mathrm{GPa}$, while for similar resin filled by 0.75 wt. $\% \mathrm{CNFs}$ this value is about $2.99 \mathrm{GPa}(11.76 \%$ higher). For Ebalta neat resin, these values are around $2.84 \mathrm{GPa}$ and resin filled by 0.5 wt. $\% \mathrm{CNFs}$ this value is about $3.16 \mathrm{GPa}$, respectively ( $11.3 \%$ higher).

The strain rate effects on the flexural properties are shown in Fig. 6. Typical bending stress versus flexural strain curves, for all strain rates, are plotted in Fig. 6a) and 6b), respectively, for Sicomin SR 8100 with 0.75 wt.\% CNFs and Ebalta AH 150 with 0.5 wt. $\%$ CNFs. Both curves exhibit two different regimens, a quasi-linear zone, which is followed by a nonlinear region where the maximum bending stress occurs. However, it is noticed that for higher strain rates the linear region is longer for both systems and considerably affect bending properties. For example, independently of the resin, higher values of strain rate promote higher bending stress and stiffness, but the highest values are always obtained when CNFs are added to the resin. A linear model, as suggested by the literature [38-40], can be fitted to the data according with the following equations:

$$
\begin{aligned}
& \sigma=a+b \times \dot{e} \\
& E=a+b \times \dot{e}
\end{aligned}
$$



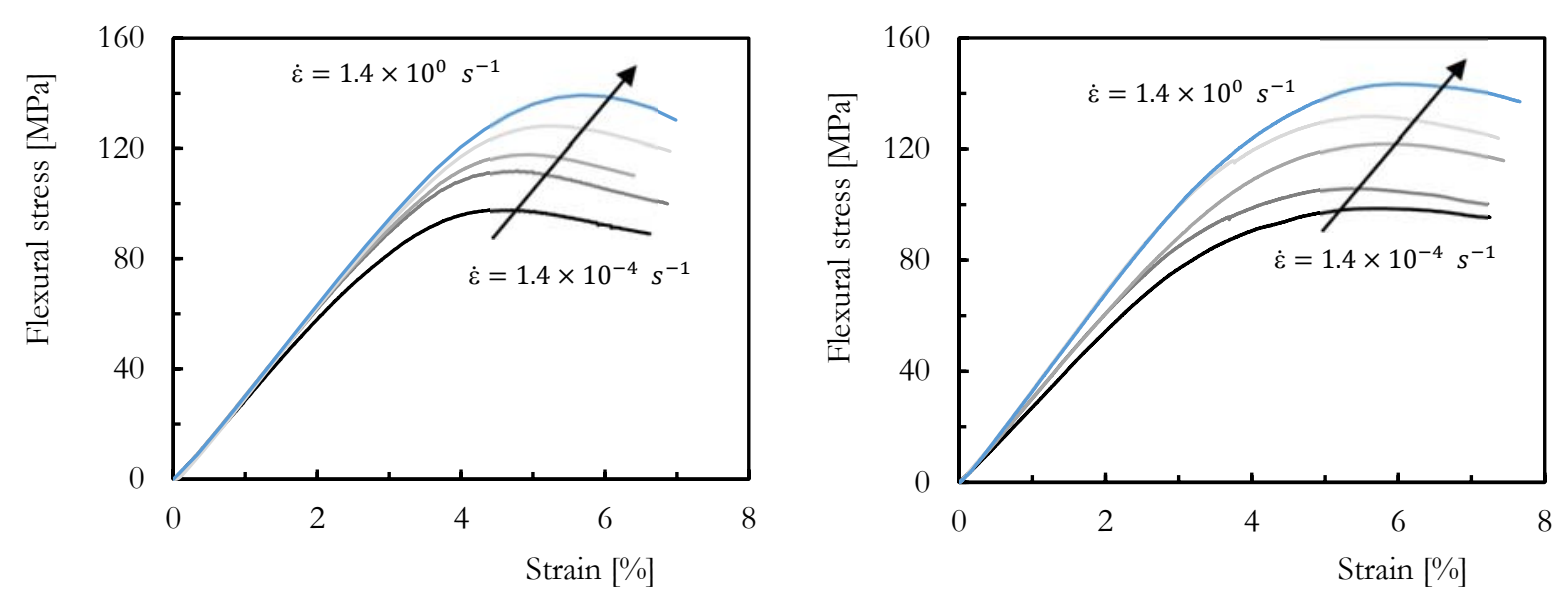

a)

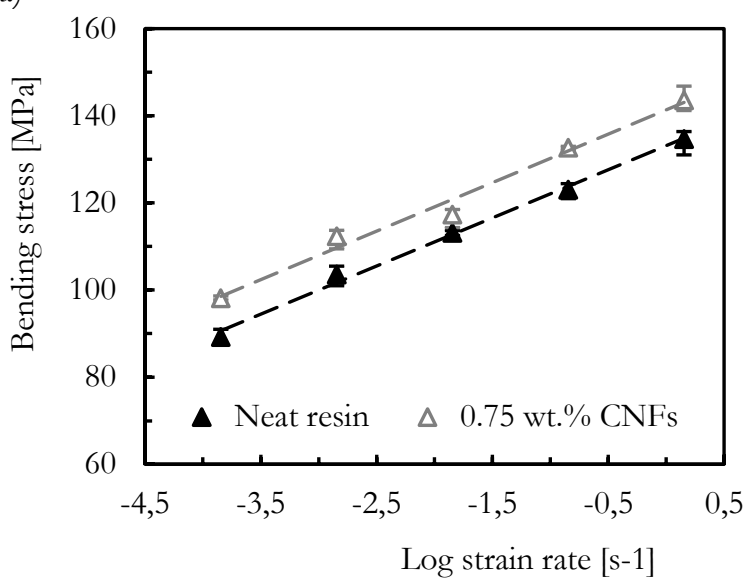

b)

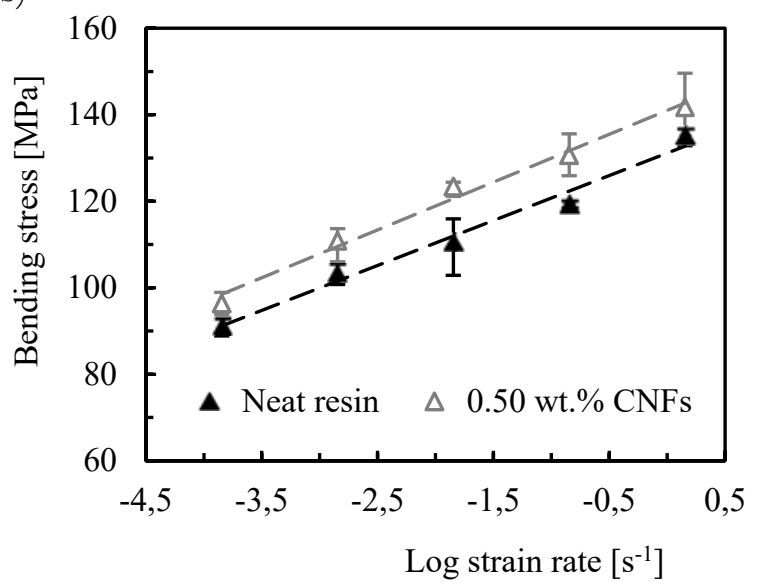

c)

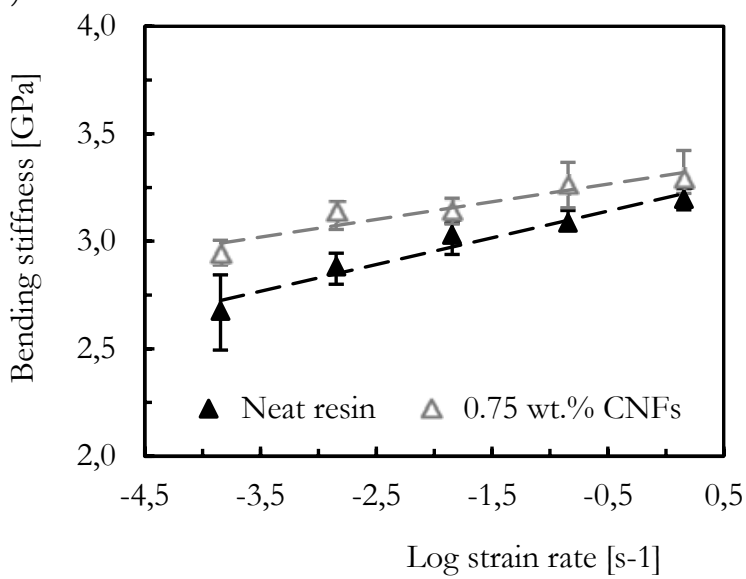

d)

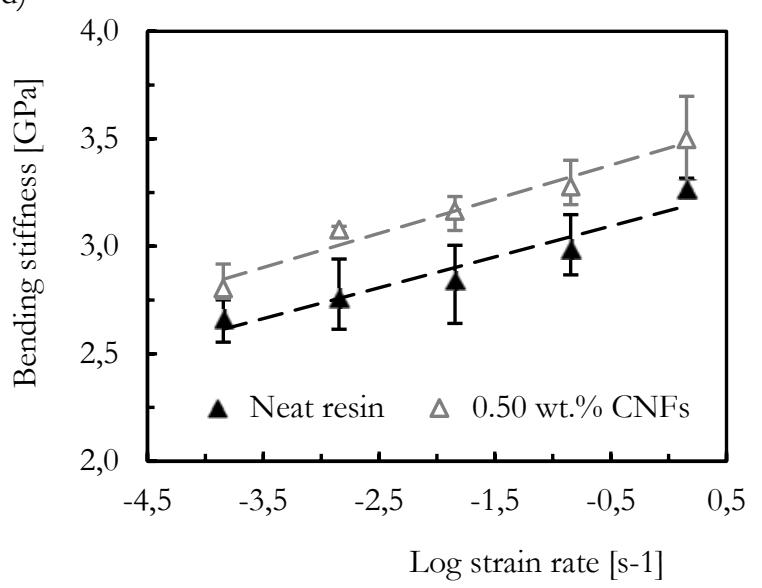

f)

Figure 6: Effect of the strain-rate: (a) For resin Sicomin SR 8100 with 0.75 wt.\% CNFs; (b) For resin Ebalta AH 150 with 0.5 wt. $\%$ CNFs; (c) Bending stress Sicomin; (d) Bending stress Ebalta; (e) Bending stiffness Sicomin; (f) Bending stiffness Ebalta; (g) Bending strain Sicomin; (h) Bending strain Ebalta.

where $\sigma$ is the maximum bending stress, $E$ is the bending modulus, $\varepsilon$ is the strain at maximum bending stress, $\dot{e}$ is the logarithm of strain rate and $a$ and $b$ constants presented in Tab. 4. From this table, it is possible to conclude that those linear relationships between the logarithm of strain rate $(\dot{\varepsilon})$ and the mechanical properties present good accuracy, and they can be used as models to predict the strain rate effect on the bending properties. 


\begin{tabular}{ccccc}
\hline \multirow{2}{*}{ Material } & Properties & \multicolumn{2}{c}{ Parameters } & Correlation coefficient \\
\cline { 3 - 4 } Neat Sicomin resin & Bending stress $(\sigma)$ & 133.12 & 11.04 & $\mathrm{R}$ \\
& Bending modulus $(E)$ & 3.20 & 0.124 & 0.997 \\
Sicomin with 0.75 wt.\% CNFs & Bending stress $(\sigma)$ & 141.34 & 11.12 & 0.977 \\
& Bending modulus $(E)$ & 3.31 & 0.082 & 0.992 \\
Neat Ebalta resin & Bending stress $(\sigma)$ & 131.13 & 10.40 & 0.947 \\
Ebalta with 0.50 wt.\% CNFs & Bending modulus $(E)$ & 3.17 & 0.144 & 0.991 \\
& Bending stress $(\sigma)$ & 141.02 & 11.06 & 0.963 \\
& Bending modulus $(E)$ & 3.46 & 0.159 & 0.994 \\
\hline
\end{tabular}

Table 4: Parameters of the equations that fits the effect of the strain-rate on the nanocomposites.

Apart from high stiffness and strength, the matrix should present viscoelastic and/or viscoplastic behaviour to eliminate brittle fracture of the composite. Good dispersion and adequate introduction of CNFs with the interfacial area and high aspect ratio into an epoxy matrix controls the long-term deformability and strength of the composite, and decrease the rate of creep strain [41]. The addition of a certain quantity of CNFs or CNT could enhance the efficiency of interfacial stress transfer thanks to an improvement in the interlaminar shear strength. However, in case of poor quality of adhesion, the damage process of the bulk resin can be accelerated, especially under shear loading, because of the increase in the number of dissipation sites, i.e. CNFs/epoxy interfaces.

With respect to viscoelastic behaviour, Fig. 7 shows the stress relaxation curves for both neat resins (Ebalta and Sicomin) and their respective CNFs nanocomposites. In these graphs, the average bending stress versus time are plotted, where $\sigma$ is the bending stress at any specific instant of the test and $\sigma_{0}$ is the initial bending stress. For all samples tested, it was noticed that, independently of the resin type and CNFs percentage, the stress decreases with time, but the neat Sicomin resin has an inferior tendency to stress relaxation than Ebalta resin. For instance, after $180 \mathrm{~min}$ and for neat Sicomin resin, this drop is about $10 \%$, while for the same resin with 0.75 wt. $\%$ CNFs is about $7.9 \%$. For Ebalta neat resin this decrease is around $14.8 \%$, and for Ebalta resin with $0.5 \mathrm{wt} . \% \mathrm{CNFs}$ is about $13.2 \%$.

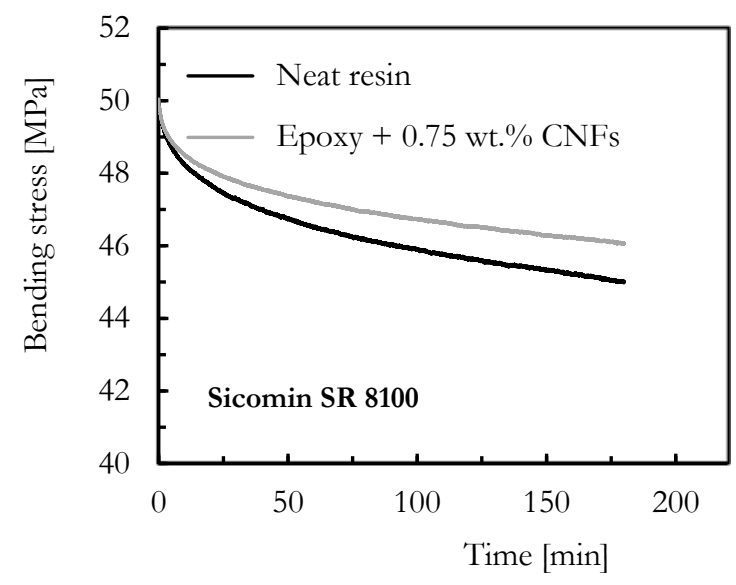

a)

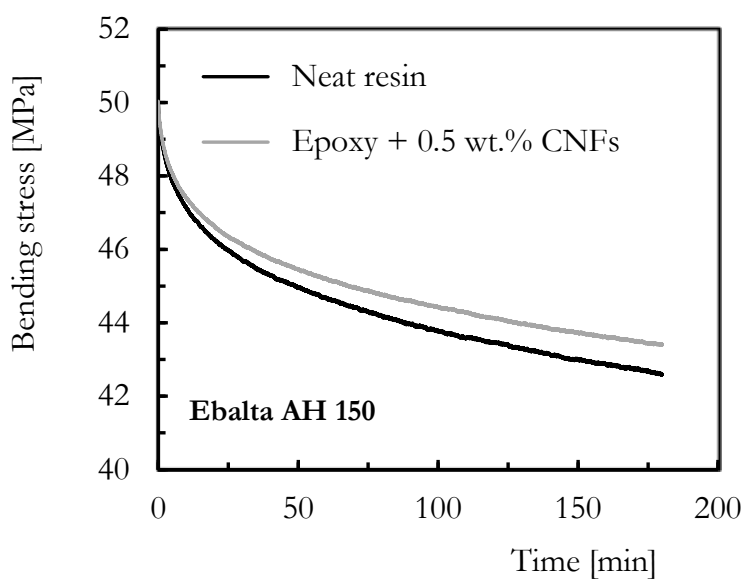

b)

Figure 7: Relaxation curves for: (a) Neat Sicomin SR 8100 and nano enhanced resin with $0.75 \mathrm{wt} . \%$ CNFs, bending stress of 50 MPa; (b) Neat Ebalta AH 150 and nano enhanced resin with 0.5 wt. $\%$ de CNFs, bending stress of $50 \mathrm{MPa}$.

For the neat resins, in the literature essentially two mechanisms are referenced that can induce stress relaxation: a) chemical stress relaxation due to chain scission and crosslinking formation or scission, and b) physical stress relaxation due to molecular rearrangements that involve little primary bonding formation or breakage [42]. However, the CNFs presence demonstrated an effective enhancement of the mechanical properties with increasing filler content, up to $0.75 \%$ for Sicomin and $0.5 \%$ for Ebalta [43]. Nonetheless, the degree of improvement showed in the results is lower than expected because the increase in mechanical performance is restricted by a concentration limit, and the great properties of CNFs are not fully 
achieved. In epoxy composites, a good load transfer efficiency combined with the dispersion state plays a relevant role in the enhancement of performance. A suboptimal dispersion state and the CNFs random orientation during the fabrication may result in an ineffective reinforcement or even negative effect. In general, the load transfer reflects the interfacial interactions: weak fillers/polymer van der Waals interactions and polymer matrix, ionic or covalent bonding when chemical treatments are applied, and the mechanical interlocking caused by unsmooth fibre surfaces. Since in this work CNFs were not chemically treated the interfacial adhesion is originated from the non-bonded interactions, which produces inefficient load transfer. Due to the fact that both cured epoxy matrixes are not the same and present important differences, their different results showed in their relaxation curves can be attributed to their different interfacial adhesion and the different physical interactions turned out from the non-identical polarity of both resins.

Regarding the creep behaviour, Fig. 8 shows typical curves obtained from the experimental tests, where the displacement is the result measured at any moment of the test $(D)$ divided by its first value $\left(D_{0}\right)$. In all curves is observed an instantaneous displacement, which depends on the stress level, and is followed by primary and secondary creep stages that are typical in creep curves. For these settings, the third stage occurs only for extended periods of time or higher stress values. In detail, Fig. 8b) shows that Ebalta resin with 0.5 wt. \% CNFs presents greater creep displacements than neat Ebalta resin. For example, the creep strain increases about $18.2 \%$ after $180 \mathrm{~min}$ for Ebalta resin with $0.5 \mathrm{wt} . \%$ CNFs and $13.2 \%$ for neat Ebalta resin. Similarly, for neat Sicomin resin and Sicomin resin with 0.75 wt. \% CNFs, this value increases $8.6 \%$ and $9.4 \%$, respectively.

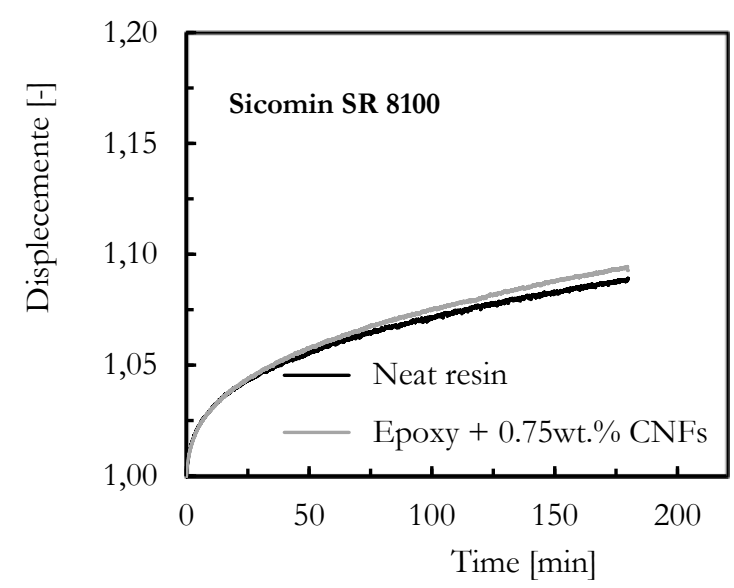

a)

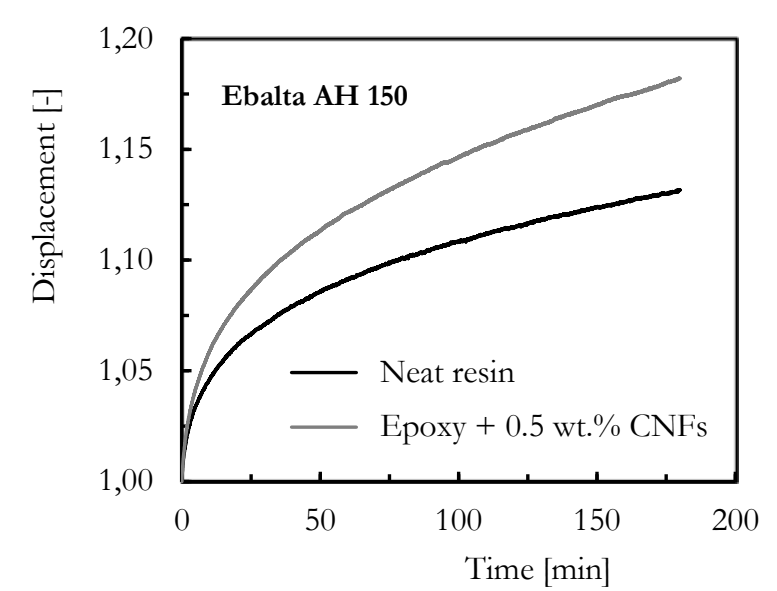

b)

Figure 8: Creep curves for: a) Neat Sicomin SR 8100 and nano-enhanced resin with 0.75 wt.\% CNFs, at bending stress of 50 MPa, b) Neat Ebalta AH 150 and nano-enhanced resin with 0.5 wt.\% CNFs, at bending stress of $50 \mathrm{MPa}$.

In this case, for neat resins, the creep is a consequence of the combining effect of viscous flow and elastic deformation [41]. According to Bouafif et al. [44], molecular motions in the backbone polymer arrangement is responsible for the creep phenomenon, and it is conditioned by the stress level. Jian et al. [45] suggested that there is a quantitative connection between molecular mobility and macroscopic deformation. A relatively low quantity of CNFs has a hindrance effect on polymer chain mobility of the epoxy matrix, as well as the chain disentanglement and slippage. It was mentioned that the presence of CNFs can hinder the motion of the epoxy polymer chains leading to an improved creep performance but depending on the filler concentration a contradictory response to the above said have also been detailed. CNFs-epoxy nanocomposites tend to exhibit time-dependent deformations on account of the inherent viscoelastic behaviour of polymers, over a wide range of temperatures which can be depicted by creep for a constant load. The presence of fillers can lead to a relevant improvement in the creep resistance. However, in the case of local aggregation of CNTs or CNFs, the creep resistance does not increase continuously with growing the filler weight fraction in particular at elevated percentages [46]. The creep response in an epoxy nanocomposite is affected by an irregular dispersion of CNFs in the matrix and a weakened filler/polymer interfacial region derived from the bad compatibility between both materials. HassanzadehAghdam et al. [46] explained that an increment in the interface thickness appeared to improve the nanocomposite creep resistance because the interface had lower compliance. The reinforcing capability in nanocomposites is weaker with higher weight fraction and creep loads as the agglomeration occurs and the filler/epoxy adhesion deteriorates [45]. However, an increment in filler weight fraction with good dispersion may result in a perceptible reduction of creep displacements. Thus, 
a greater comprehension of the creep deformation and the reinforcing mechanism of creep resistance in nanocomposites at the molecular level is still imperative because the creep response is a matter of concern for long-term durability of these materials [47].

One the one hand, from the comparison of the creep curves for neat Sicomin SR 8100 and nano-enhanced resin with 0.75 wt.\% de CNFs it can be observed that the effect of the filler presence is almost irrelevant, neither positive nor detrimental. there was a slight increment of creep displacement, especially after 50-75 minutes, which shows a slightly negative effect of the CNFs in the long-term durability. One the other hand, for the neat Ebalta AH 150 and the nano-enhanced resin with $0.5 \mathrm{wt} . \%$ de CNFs, it can be clearly observed the negative effect of the fillers in the overall creep behaviour. The Ebalta based nanocomposite creep displacement increases noticeably respect to the pristine resin meaning that the creep resistance decreases in an important way. The harmful effects of a weakened filler/polymer interfacial region and/or the bad state of dispersion of CNFs into the polymer matrix are detected in the Ebalta sample. The reason may come from the different physical interactions yield from the distinctive polarities of both resins since their chemical compositions are not identical.

\section{CONCLUSIONS}

$\mathrm{D}$ ifferent percentages of CNFs were used to improve the mechanical properties of two commercial epoxy resin, particularly their static and viscoelastic properties.

It was possible to observe that, independently of the epoxy resin, higher values of CNFs added to the resin promoted higher flexural stress and modulus. The best weight content was 0.75\% for Sicomin SR 8100 and 0.5\% for Ebalta AH 150.

Regarding the strain-rate sensitivity, independently of the resin and nanocomposite, it was possible to observe that both materials are strain-rate sensitivity. The bending stress and modulus increase for higher values of strain rate.

Finally, from the stress relaxation tests, it is clear that stress is reduced over time, but when the CNFs are added to the resins, they are less prone to stress relaxation. In the case of creep response, the displacement increases with time for all systems, but, in this case, nanocomposites are more prone to creep.

\section{ACKNOWLEDGEMENTS}

7 his work was supported by the project Centro-01-0145-FEDER-000017 - EMaDeS - Energy, Materials and Sustainable Development, co-financed by the Portugal 2020 Program (PT 2020), within the Regional Operational Program of the Center (CENTRO 2020) and the European Union through the European Regional Development Fund (ERDF).

\section{REFERENCES}

[1] Kancherla, K.B., Subbappa, D.B., Hiremath, S.R., Raju, B., Roy Mahapatra, D. (2019). Enhancing mechanical properties of glass fabric composite with surfactant treated zirconia nanoparticles, Compos. Part A Appl. Sci. Manuf., 118(September 2018), pp. 131-41, DOI: 10.1016/j.compositesa.2018.12.023.

[2] Balasubramaniam, B., Sathiyan, G., Palani, G.S., Iyer, N.R., Gupta, R.K. (2019).Fiber Reinforced Polymer Nanocomposites for Structural Engineering Applications. Materials Science and Technology, Wiley, pp. 1-20.

[3] Licari, J.J., Swanson, D.W. (2011).Chapter 3 - Chemistry, Formulation, and Properties of Adhesives. Adhesives Technology for Electronic Applications, Elsevier, pp. 75-141.

[4] Fiore, V., Valenza, A. (2013).Epoxy resins as a matrix material in advanced fiber-reinforced polymer (FRP) composites. Advanced Fibre-Reinforced Polymer (FRP) Composites for Structural Applications, Elsevier, pp. 88-121.

[5] Takeichi, T., Furukawa, N. (2012).Epoxy Resins and Phenol-Formaldehyde Resins. Polymer Science: A Comprehensive Reference, vol. 5, Elsevier, pp. 723-51.

[6] Reis, P.N.B., Ferreira, J.A.M., Santos, P., Richardson, M.O.W., Santos, J.B. (2012). Impact response of Kevlar composites with filled epoxy matrix, Compos. Struct., 94(12), pp. 3520-8, DOI: 10.1016/j.compstruct.2012.05.025.

[7] Kaybal, H.B., Ulus, H., Demir, O., Şahin, Ö.S., Avc1, A. (2018). Effects of alumina nanoparticles on dynamic impact responses of carbon fiber reinforced epoxy matrix nanocomposites, Eng. Sci. Technol. an Int. J., 21(3), pp. 399-407, DOI: $10.1016 /$ j.jestch.2018.03.011.

[8] Shen, M.-Y., Chang, T.-Y., Hsieh, T.-H., Li, Y.-L., Chiang, C.-L., Yang, H., Yip, M.-C. (2013). Mechanical Properties 
and Tensile Fatigue of Graphene Nanoplatelets Reinforced Polymer Nanocomposites, J. Nanomater., 2013, pp. 1-9, DOI: $10.1155 / 2013 / 565401$.

[9] Gao, X., Lan, J., Jia, X., Cai, Q., Yang, X. (2016). Improving interfacial adhesion with epoxy matrix using hybridized carbon nanofibers containing calcium phosphate nanoparticles for bone repairing, Mater. Sci. Eng. C, 61, pp. 174-9, DOI: $10.1016 /$ j.msec.2015.12.033.

[10] Liu, X., Yue, D., Yang, C., Li, N., Gao, S., Liu, Y., Mo, G., Wu, Z., Yin, J., Su, B., Li, L. (2019). Fluorinated carbon nanofiber/polyimide composites: Electrical, mechanical, and hydrophobic properties, Surf. Coatings Technol., 361(August 2018), pp. 206-11, DOI: 10.1016/j.surfcoat.2019.01.033.

[11] Liu, W., Wang, Y., Wang, P., Li, Y., Jiang, Q., Hu, X., Wei, Y., Qiu, Y., Shahabadi, S.I.S., Lu, X. (2017). A biomimetic approach to improve the dispersibility, interfacial interactions and toughening effects of carbon nanofibers in epoxy composites, Compos. Part B Eng., 113, pp. 197-205, DOI: 10.1016/j.compositesb.2017.01.040.

[12] Gantayat, S., Rout, D., Swain, S.K. (2017). Structural and mechanical properties of functionalized carbon nanofiber/epoxy nanocomposites, Mater. Today Proc., 4(8), pp. 9060-4, DOI: 10.1016/j.matpr.2017.07.259.

[13] Buchanan, J.P., Reed-Gore, E.R., Jefcoat, J.A., Moser, R.D., Klaus, K.L., Peel, H.R., Buchanan, R.K., Barnes, E., Alberts, E.M., Shukla, M.K. (2019). Increasing mechanical resilience and enhanced electrical conductivity through the incorporation of CNF reinforcing additives in PA6 nanocomposites, Struct. Chem., 30(1), pp. 341-9, DOI: 10.1007/s11224-018-1236-8.

[14] Zhou, Y., Akanda, S.R., Jeelani, S., Lacy, T.E. (2007). Nonlinear constitutive equation for vapor-grown carbon nanofiber-reinforced SC-15 epoxy at different strain rate, Mater. Sci. Eng. A, 465(1-2), pp. 238-46, DOI: 10.1016/j.msea.2007.04.042.

[15] Poveda, R.L., Gupta, N. (2016). Change in failure mode of carbon nanofibers in nanocomposites as a function of loading rate, J. Mater. Sci., 51(10), pp. 4917-27, DOI: 10.1007/s10853-016-9796-8.

[16] Zare, Y. (2016). The roles of nanoparticles accumulation and interphase properties in properties of polymer particulate nanocomposites by a multi-step methodology, Compos. Part A Appl. Sci. Manuf., 91, pp. 127-32, DOI: 10.1016/j.compositesa.2016.10.003.

[17] Oberdisse, J. (2006). Aggregation of colloidal nanoparticles in polymer matrices, Soft Matter, 2(1), pp. 29-36, DOI: 10.1039/B511959F.

[18] Padmanabhan, V., Frischknecht, A.L., MacKay, M.E. (2012). Effect of chain stiffness on nanoparticle segregation in polymer/nanoparticle blends near a substrate, Macromol. Theory Simulations, 21(2), pp. 98-105, DOI: 10.1002/mats.201100048.

[19] Ma, X., Zare, Y., Rhee, K.Y. (2017). A Two-Step Methodology to Study the Influence of Aggregation/Agglomeration of Nanoparticles on Young's Modulus of Polymer Nanocomposites, Nanoscale Res. Lett., 12, pp. 0-6, DOI: 10.1186/s11671-017-2386-0.

[20] Shaffer, M.S.P., Fan, X., Windle, A.H. (1998). Dispersion and packing of carbon nanotubes, Carbon N. Y., 36(11), pp. 1603-12, DOI: 10.1016/S0008-6223(98)00130-4.

[21] Fiedler, B., Gojny, F.H., Wichmann, M.H.G., Nolte, M.C.M., Schulte, K. (2006). Fundamental aspects of nanoreinforced composites, Compos. Sci. Technol., 66(16), pp. 3115-25, DOI: 10.1016/j.compscitech.2005.01.014.

[22] Liu, S., Chevali, V.S., Xu, Z., Hui, D., Wang, H. (2018). A review of extending performance of epoxy resins using carbon nanomaterials, Compos. Part B Eng., 136, pp. 197-214, DOI: 10.1016/j.compositesb.2017.08.020.

[23] Ignatenko, V.Y., Ilyin, S.O., Kostyuk, A. V., Bondarenko, G.N., Antonov, S. V. (2020). Acceleration of epoxy resin curing by using a combination of aliphatic and aromatic amines, Polym. Bull., 77(3), pp. 1519-40, DOI: 10.1007/s00289-019-02815-x.

[24] Garcia, F.G., Soares, B.G., Pita, V.J.R.R., Sánchez, R., Rieumont, J. (2007). Mechanical properties of epoxy networks based on DGEBA and aliphatic amines, J. Appl. Polym. Sci., 106(3), pp. 2047-55, DOI: 10.1002/app.24895.

[25] Baig, Z., Akram, N., Zia, K.M., Saeed, M., Khosa, M.K., Ali, L., Saleem, S. (2020). Influence of amine-terminated additives on thermal and mechanical properties of diglycidyl ether of bisphenol A (DGEBA) cured epoxy, J. Appl. Polym. Sci., 137(8), pp. 48404, DOI: 10.1002/app.48404.

[26] Cai, H., Li, P., Sui, G., Yu, Y., Li, G., Yang, X., Ryu, S. (2008). Curing kinetics study of epoxy resin/flexible amine toughness systems by dynamic and isothermal DSC, Thermochim. Acta, 473(1-2), pp. 101-5, DOI: 10.1016/j.tca.2008.04.012.

[27] Nie, Y., Hübert, T. (2011). Effect of carbon nanofiber (CNF) silanization on the properties of CNF/epoxy nanocomposites, Polym. Int., 60(11), pp. 1574-80, DOI: 10.1002/pi.3124.

[28] Bal, S. (2010). Experimental study of mechanical and electrical properties of carbon nanofiber/epoxy composites, Mater. Des., 31(5), pp. 2406-13, DOI: 10.1016/j.matdes.2009.11.058. 
[29] Wu, Q., Zhao, R., Ma, Q., Zhu, J. (2018). Effects of degree of chemical interaction between carbon fibers and surface sizing on interfacial properties of epoxy composites, Compos. Sci. Technol., 163(December 2017), pp. 34-40, DOI: 10.1016/j.compscitech.2018.05.013.

[30] Prolongo, S.G., Burón, M., Gude, M.R., Chaos-Morán, R., Campo, M., Ureña, A. (2008). Effects of dispersion techniques of carbon nanofibers on the thermo-physical properties of epoxy nanocomposites, Compos. Sci. Technol., 68(13), pp. 2722-30, DOI: 10.1016/j.compscitech.2008.05.015.

[31] Zhu, J., Wei, S., Ryu, J., Budhathoki, M., Liang, G., Guo, Z. (2010). In situ stabilized carbon nanofiber (CNF) reinforced epoxy nanocomposites, J. Mater. Chem., 20(23), pp. 4937-48, DOI: 10.1039/c0jm00063a.

[32] Wang, J., Gong, J., Gong, Z., Yan, X., Wang, B., Wu, Q., Li, S. (2010). Effect of curing agent polarity on water absorption and free volume in epoxy resin studied by PALS, Nucl. Instruments Methods Phys. Res. Sect. B Beam Interact. with Mater. Atoms, 268(14), pp. 2355-61, DOI: 10.1016/j.nimb.2010.04.010.

[33] Sandler, S.R., Berg, F.R. (1965). Effect of polarity of bisphenol a epoxy resins on adhesion at cryogenic and elevated temperatures, J. Appl. Polym. Sci., 9(11), pp. 3707-19, DOI: 10.1002/app.1965.070091118.

[34] Wilson, A.D., Stewart, F.F. (2014). Structure-function study of tertiary amines as switchable polarity solvents, RSC Adv., 4(22), pp. 11039-49, DOI: 10.1039/c3ra47724j.

[35] Tao, K., Yang, S., Grunlan, J.C., Kim, Y.S., Dang, B., Deng, Y., Thomas, R.L., Wilson, B.L., Wei, X. (2006). Effects of carbon nanotube fillers on the curing processes of epoxy resin-based composites, J. Appl. Polym. Sci., 102(6), pp. 5248-54, DOI: 10.1002/app.24773.

[36] Seyhan, A.T., Sun, Z., Deitzel, J., Tanoglu, M., Heider, D. (2009). Cure kinetics of vapor grown carbon nanofiber (VGCNF) modified epoxy resin suspensions and fracture toughness of their resulting nanocomposites, Mater. Chem. Phys., 118(1), pp. 234-42, DOI: 10.1016/j.matchemphys.2009.07.045.

[37] Dutta, A., Ryan, M.E. (1979). Effect of fillers on kinetics of epoxy cure, J. Appl. Polym. Sci., 24(3), pp. 635-49, DOI: 10.1002/app.1979.070240302.

[38] Ingram, J., Zhou, Y., Jeelani, S., Lacy, T., Horstemeyer, M.F. (2008). Effect of strain rate on tensile behavior of polypropylene and carbon nanofiber filled polypropylene, Mater. Sci. Eng. A, 489(1-2), pp. 99-106, DOI: 10.1016/j.msea.2008.01.010.

[39] Delhaye, V., Clausen, A.H., Moussy, F., Othman, R., Hopperstad, O.S. (2011). Influence of stress state and strain rate on the behaviour of a rubber-particle reinforced polypropylene, Int. J. Impact Eng., 38(4), pp. 208-18, DOI: 10.1016/j.ijimpeng.2010.11.004.

[40] Reis, P.N.B., Gorbatikh, L., Ivens, J., Lomov, S.V. (2019). Strain-rate sensitivity and stress relaxation of hybrid selfreinforced polypropylene composites under bending loads, Compos. Struct., 209(August 2018), pp. 802-10, DOI: 10.1016/j.compstruct.2018.11.030.

[41] Glaskova-Kuzmina, T., Aniskevich, A., Zarrelli, M., Martone, A., Giordano, M. (2014). Effect of filler on the creep characteristics of epoxy and epoxy-based CFRPs containing multi-walled carbon nanotubes, Compos. Sci. Technol., 100, pp. 198-203, DOI: 10.1016/j.compscitech.2014.06.011.

[42] Reis, P.N.B., Silva, M.P., Santos, P., Parente, J.M., Valvez, S., Bezazi, A. (2020). Mechanical performance of an optimized cork agglomerate core-glass fibre sandwich panel, Compos. Struct., 245, pp. 112375, DOI: 10.1016/j.compstruct.2020.112375.

[43] Jian, W., Lau, D. (2020). Understanding the effect of functionalization in CNT-epoxy nanocomposite from molecular level, Compos. Sci. Technol., 191(November 2019), pp. 108076, DOI: 10.1016/j.compscitech.2020.108076.

[44] Bouafif, H., Koubaa, A., Perré, P., Cloutier, A. (2013). Creep behaviour of HDPE/wood particle composites, Int. J. Microstruct. Mater. Prop., 8(3), pp. 225, DOI: 10.1504/IJMMP.2013.055385.

[45] Jian, W., Lau, D. (2019). Creep performance of CNT-based nanocomposites: A parametric study, Carbon N. Y., 153, pp. 745-56, DOI: 10.1016/j.carbon.2019.07.069.

[46] Hassanzadeh-Aghdam, M.K., Mahmoodi, M.J., Ansari, R. (2019). Creep performance of CNT polymer nanocomposites -An emphasis on viscoelastic interphase and CNT agglomeration, Compos. Part B Eng., 168(August 2018), pp. 274-81, DOI: 10.1016/j.compositesb.2018.12.093.

[47] Nomula, S.S.R., Rathore, D.K., Ray, B.C., Prusty, R.K. (2019). Creep performance of CNT reinforced glass fiber/epoxy composites: Roles of temperature and stress, J. Appl. Polym. Sci., 136(25), pp. 47674, DOI: 10.1002/app.47674. 